\section{Deficiência de Magnésio e Resistência à Insulina em Pacientes com Diabetes Mellitus Tipo 2}

\section{RESUMO}

magnésio é um íon predominantemente intra-celular, que participa como co-fator de mais de 300 reações enzimáticas, dentre elas na atividade da tirosino-cinase. Sua deficiência pode aumentar a resistência periférica à insulina, especialmente em pacientes com síndrome metabólica e diabetes mellitus tipo 2 (DM2). Este trabalho avaliou, em 27 pacientes com DM2 descompensado, o conteúdo intra-celular de magnésio, correlacionando-o com índices laboratoriais de resistência insulínica e controle glicêmico. Hipomagnesemia foi encontrada em $75 \%$ dos pacientes e déficit intra-celular em 30,8\%. Houve correlação negativa do Mg intra-celular (Mg IC) com HbAl e com IMC. 59,2\% dos pacientes apresentaram HOMA IR $\geq 3,5$, e tendência para correlação negativa com o Mg IC, porém sem significância estatística. Apesar do número pequeno de pacientes, ressalta-se que uma vez que deficiência de magnésio é comum em pacientes com diabetes, sua relação com resistência insulínica deve ser mais estudada. (Arq Bras Endocrinol Metab 2005;49/6:959-963)

Descritores: Diabetes mellitus; Magnésio; Resistência à insulina

\section{ABSTRACT}

Magnesium Deficiency and Insulin Resistance in Patients With Type 2 Diabetes Mellitus.

Magnesium is a predominantly intracellular ion, and it is a cofactor in more than 300 enzymatic reactions, like tyrosinokinase activity. Its deficiency may increase insulin resistance, especially in patients with metabolic syndrome or type 2 diabetes. This study evaluated in 27 patients with poorly controlled type 2 diabetes if there was correlation between intracellular magnesium levels, laboratorial indexes of insulin resistance and glycemic control. Decreased serum and intracellular magnesium depletion were found in $75 \%$ and $30.8 \%$ of patients, respectively. A negative correlation between intracellular magnesium levels (ICMg) and $\mathrm{BMl}$ and $\mathrm{HbAl}$ was found. The homeostasis model assessment for insulin resistance (HOMA-IR) was higher than 3.0 in $59.2 \%$ of patients and there was a tendency to negative correlation with ICMg levels, although without statistical significance. Despite the small number of patients, this study shows that magnesium deficiency is frequent in patients with diabetes and its correlation with insulin resistance should be more studied. (Arq Bras Endocrinol Metab 2005;49/6:959-963)

Keywords: Diabetes mellitus; Magnesium; Insulin resistance

$\mathrm{O}$ MAGNÉSIO É UM ÍON PREDOMINANTEMENTE INTRA-CELULAR, participando como co-fator de mais de 300 reações enzimáticas, modulando o transporte da glicose através das membranas, envolvendo-se em diversas ações enzimáticas que influem na oxidação da glicose, podendo a sua artigo original

\author{
Maria de Lourdes Lima \\ Judith Pousada \\ Cynara Barbosa \\ Thomaz Cruz
}

Ambulatório de Diabetes, Hospital Universitário Professor Edgard Santos, Universidade Federal da Bahia, Salvador, BA. 
deficiência contribuir para resistência à insulina, ou ser conseqüência dela $(1,2)$. Várias evidências mostram relação entre hipomagnesemia e atividade da tirosinoquinase ao nível do receptor da insulina, o que pode gerar maior resistência periférica à ação da insulina (3).

Hipomagnesemia tem sido relatada em 25 a $47 \%$ dos diabéticos, especialmente naqueles sem bom controle metabólico (4-11). Além disso, deficiência de magnésio é forte preditor para o desenvolvimento de diabetes (12). Num braço do Women's Health Study (WHS), Song e cols. mostraram que, quanto maior a ingesta de magnésio, menor a incidência de diabetes na população prospectivamente estudada, especialmente nas mulheres com sobrepeso (13).

$\mathrm{O}$ grande aumento da prevalência mundial do diabetes mellitus deve-se em parte ao aumento também crescente na prevalência do excesso de peso, com a conseqüente síndrome metabólica, na qual a resistência à insulina é aspecto fisiopatológico central (1417). Alguns autores têm correlacionado deficiência de magnésio e resistência à insulina (2). Guerrero Romero demonstrou, numa população de 192 pacientes com síndrome metabólica, 65,6\% de hipomagnesemia, comparada com $4,9 \%$ no grupo controle (18).

O objetivo deste trabalho foi avaliar a freqüência da deficiência de magnésio sérico e intracelular em uma população de pacientes com diabetes mellitus tipo 2 , correlacionando estes dados com parâmetros laboratoriais de controle metabólico e de resistência à insulina.

\section{MATERIAL E MÉTODOS}

Foram avaliados 27 pacientes com diabetes mellitus tipo 2, 19 mulheres e 8 homens, com idade de 50,9 \pm 9,0 anos (34 a 70 anos), duração do diabetes $6,1 \pm 5,2$ anos $\left(2\right.$ meses a 20 anos), IMC: $25,4 \pm 6,7 \mathrm{Kg} / \mathrm{m}^{2}(20$ a $\left.33,7 \mathrm{Kg} / \mathrm{m}^{2}\right)$, acompanhados no ambulatório de diabetes do Hospital Universitário Professor Edgard Santos, em Salvador, Bahia. Os pacientes eram tratados apenas com dieta ou em associação com hipoglicemiantes orais, mas com controle metabólico insatisfatório, que foi definido como a média das três últimas glicemias de jejum estando acima de $140 \mathrm{mg} / \mathrm{dl}$ num intervalo máximo de 90 dias, e/ou hemoglobina glicosilada (HbAl) acima de 8,0\% (VR: 5 a 8\%).

Os critérios de exclusão adotados foram: diminuição da função renal, comprovada através da depuração da creatinina inferior a $70 \mathrm{ml} / \mathrm{min} / 1,73 \mathrm{~m}^{2}$; idade superior a 70 anos; uso de diuréticos, uso de insulina como tratamento hipoglicemiante e recusa em participar do estudo.
Para avaliação dos níveis normais do magnésio na nossa população foram avaliados 64 doadores de sangue saudáveis, sendo $22(34,4 \%)$ mulheres e 42 $(66,6 \%)$ homens, com idade de $32,0 \pm 8,6$ anos (18 a 54 anos).

O trabalho foi aprovado pelo Comitê de Ética do Hospital Universitário Professor Edgard Santos da Universidade Federal da Bahia, onde foi realizado o estudo.

Os pacientes preencheram ficha de avaliação padronizada após assinatura do termo de consentimento informado. Depois de 12 horas de jejum foi colhido sangue para realização dos seguintes exames laboratoriais: magnésio plasmático, por espectrofotometria de absorção atômica (VR: 1,40 a 1,64mEq/1); magnésio na urina de 24 horas, pelo método colorimétrico (VR: 50 a 150mg/24h); glicemia sérica de jejum, pelo método da glicose-oxidase (VR: 70 a $110 \mathrm{mg} / \mathrm{dl})$; hemoglobina glicosilada $(\mathrm{HbAl})$ por resina de troca iônica (VR: 5,0 a 8,0\%); insulina, por radioimunoensaio (VR: 5 a $35 \mu \mathrm{U} / \mathrm{ml}$ ); frutosamina por azul de nitrotetrazólio (NBT) (VR: 1,87 a 2,87mmol/1); magnésio intra-mononuclear pelo método da espectrofotometria de absorção atômica, expresso em mg de proteína (VR: 1,07 a 2,31 $\mu \mathrm{g} / \mathrm{mg}$ de proteína).

Foram utilizadas células sangüíneas mononucleares para determinação do magnésio intracelular, isoladas do sangue periférico, separadas por gradiente de densidade em meio Ficcol 400/metrizoato de sódio, da seguinte forma: coleta de $10 \mathrm{ml}$ de sangue em tubo heparinizado, colocado sob $3 \mathrm{ml}$ de meio separador de linfócitos (Hystopaque 1077); centrifugação a $400 \mathrm{~g}$ por 30 minutos; o plasma foi separado e congelado para determinação do magnésio plasmático. $\mathrm{O}$ anel de linfócitos foi aspirado, utilizando-se pipetas do tipo Pasteur, sendo transferido para outro tubo ao qual foi acrescentado $3 \mathrm{ml}$ de salina, centrifugado por 10 minutos a $400 \mathrm{~g}$, tendo-se desprezado o sobrenadante. Este processo foi repetido mais duas vezes. $\mathrm{O}$ extrato de células foi diluído em $3 \mathrm{ml}$ de salina e congelado. A suspensão final destas células revela contagem diferencial final de 60 a $92 \%$ de linfócitos; 5 a $35 \%$ de monócitos; 0 a $3 \%$ de neutrófilos, $1 \%$ de basófilos; e contaminação eritrocitária negligenciável (19). O congelamento e descongelamento sucessivos propiciam a lise das células, permitindo a determinação do magnésio por espectrofotometria de absorção atômica e determinação de proteínas contidas no meio pela técnica de Lowry modificada (20). Todo o material usado na técnica de separação das células mononucleares foi imerso em solução de ácido clorídrico a $10 \%$ e em seguida lavado com água deionizada. Para 
expressão final do teor do magnésio, divide-se o resultado da leitura do magnésio em $\mu \mathrm{g} / \mathrm{ml}$, pela determinação da proteína, em $\mathrm{mg} / \mathrm{ml}$, ficando o resultado final, em $\mu \mathrm{g} / \mathrm{mg}$ de proteína.

A avaliação laboratorial da resistência à insulina foi feita pelo HOMA r, que foi calculado pela fórmula: glicemia $(\mathrm{em} \mathrm{mmol} / \mathrm{l}) \mathrm{x}$ insulinemia $(\mathrm{em} \mu \mathrm{U} / \mathrm{l}) / 22,5$; e o HOMA B: $20 \mathrm{x}$ insulinemia / glicemia - 3,5 (21).

Análise estatística: Os dados foram apresentados em médias e desvio-padrão. $\mathrm{Na}$ análise de variáveis possivelmente inter-relacionadas foi utilizado o coeficiente de correlação de Pearson. Significância estatística foi considerada quando o valor de $\mathrm{p}$ foi $<0,05$. Os dados foram analisado no programa SPSS Statistical Package for the Social Science, versão 9.0.1.

\section{RESULTADOS}

Dos 27 pacientes avaliados, 55,6\% eram hipertensos. $\mathrm{O}$ tratamento para o diabetes era feito com glibenclamida em 23 pacientes $(85,2 \%)$, metformina em 3 pacientes $(11,1 \%)$ e apenas um $(3,7 \%)$ usava a combinação das duas drogas.

Os exames laboratoriais para avaliação do controle metabólico e dos níveis do magnésio são apresentados na tabela 1 . A avaliação da sensibilidade à insulina foi feita através do HOMA r, que apresentou valores entre 0,28 a 32,6, e o HOMA B, que variou 1,7 a 473 . Considerando que HOMA $\geq 3,5$ é indicador de resistência insulínica (22), 16 pacientes (59,2\%) apresentaram sensibilidade à insulina diminuída. Apenas 3 pacientes apresentaram HOMA B > 100\%, o que demonstrou redução da secreção de insulina na maioria $(88,9 \%)$ dos pacientes.

Quinze pacientes $(55,6 \%)$ estavam acima do peso, e, destes, 4 (14,3\%) apresentavam índice de massa corpórea $\left(\right.$ IMC) $>30 \mathrm{Kg} / \mathrm{m}^{2}$. Hipomagnesemia es-

Tabela 1. Parâmetros de controle glicêmico e magnésio $(\mathrm{Mg})$ em 27 pacientes com diabetes mellitus tipo 2 metabolicamente descompensados.

\begin{tabular}{lccc}
\hline Exame & Valor encontrado & Variação & Valor de referência \\
\hline $\begin{array}{l}\text { Glicemia jejum } \\
\text { (mg/dl) }\end{array}$ & $247 \pm 86$ & 168 a 230 & 70 a 110 \\
$\begin{array}{l}\text { Hemoglobina } \\
\text { glicosilada (\%) }\end{array}$ & $9,7 \pm 2,5$ & 8,04 a 15,8 & 5,0 a 8,0 \\
$\begin{array}{l}\text { Mg++ plasmático } \\
\text { (mEq/l) }\end{array}$ & $1,17 \pm 0,16$ & 1,0 a 1,4 & $1,4 \pm 1,64$ \\
$\begin{array}{l}\text { Mg }++ \text { linfocitário } \\
\text { ( } \begin{array}{l}\text { Mg/mg de proteína) } \\
\text { Mg++ urinário }\end{array}\end{array}$ & $1,48 \pm 0,8$ & 0,57 a 2,57 & 1,07 a 2,31 \\
(mg/24 horas) & $89,5 \pm 40,5$ & 30 a 180 & 50 a 150 \\
\hline
\end{tabular}

teve presente em $75 \%$ dos pacientes e déficit intracelular em 30,8\%, ambos significativamente mais baixos do que na população de referência (tabela 2 ).

Observamos correlação inversa entre magnésio linfocitário e IMC $(\mathrm{r}=-0,460 ; \mathrm{p}=0,04)$, e entre magnésio intra-linfocitário e hemoglobina glicosilada $(\mathrm{r}=$ $-0,481 ; p<0,05)$. Não houve diferença significante de deficiência intra-celular de magnésio entre os hipertensos e não hipertensos $(21,4 \%$ e $18,2 \%$ respectivamente).

Observou-se, ainda, uma tendência à correlação negativa, porém não estatisticamente significante, entre o magnésio intra-celular e o HOMA $\mathrm{r}(\mathrm{r}=-0,286$; $\mathrm{p}=0,17)$, acentuando-se quando selecionados os pacientes com resistência à insulina (HOMA $\mathrm{r} \geq 3,5$ ), mas ainda sem significância estatística: $(r=-0,402 ; p=$ $0,09)$. As correlações entre as demais variáveis e o magnésio sérico e intracelular não foram estatisticamente significantes. Analisando separadamente o grupo de pacientes com mais de 5 anos de doença e com menos de 5 anos, não se observaram diferenças relacionadas à correlação entre magnésio e resistência insulínica.

\section{DISCUSSĀO}

A deficiência de magnésio, apesar de pouco pesquisada, é muito freqüente na população com diabetes. Vinte e cinco a $47 \%$ dos indivíduos com diabetes apresentam hipomagnesemia (4-11), enquanto numa população saudável este déficit está presente, em geral, em $4,9 \%$ dos indivíduos (18), o que mostra claramente uma maior prevalência da deficiência de magnésio em pacientes com diabetes mellitus.

Neste trabalho observamos hipomagnesemia em $75 \%$ da população estudada, percentual acima daquele descrito na literatura, mas que pode ser explicado pelo mau controle glicêmico dos pacientes estudados. A maioria dos trabalhos mostra correlação inversa entre controle glicêmico e níveis de magnésio (4).

Tabela 2. Comparação dos níveis de Mg entre pacientes 27 diabéticos e a população de referência (doadores de sangue)

\begin{tabular}{lcc}
\hline & $\begin{array}{c}\text { Pacientes com } \\
\text { diabetes }(n=27)\end{array}$ & $\begin{array}{c}\text { População de } \\
\text { referência }(n=64)\end{array}$ \\
\hline $\mathrm{Mg}^{++}$plasma (mEq/l) & $1,17 \pm 0,16^{*}$ & $1,57 \pm 0,17$ \\
$\mathrm{Mg}^{++}$intramononuclear & $1,48 \pm 0,8^{*}$ & $1,69 \pm 0,62$ \\
$(\mu \mathrm{g} / \mathrm{mg}$ de proteínas) & & \\
${ }^{*} \mathrm{p}<0,05$ & &
\end{tabular}


O magnésio intra-celular esteve abaixo do normal em 30,8\% dos pacientes, valores comparáveis aos da amostra total do estudo que originou este trabalho (31\%) (11). Não há na literatura outros dados comparáveis de magnésio em linfócitos de pacientes com diabetes. Na população de doadores de sangue utilizada como controle, tanto os níveis séricos como os intracelulares foram maiores do que nos pacientes com diabetes, confirmando a freqüente redução do conteúdo corporal do magnésio nestes indivíduos.

Como era esperado, houve correlação inversa entre níveis de magnésio intra-celular com a $\mathrm{HbA}_{1}$, mostrando que quanto maior o déficit de magnésio, pior o controle metabólico. Não foi demonstrado aumento na excreção urinária do magnésio, o que reduz a possibilidade de a deficiência do magnésio ser apenas conseqüência da hiperglicemia.

Sendo o magnésio íon predominantemente intracelular, a sua determinação em soro e plasma pode não ser representativa do conteúdo corporal total, e significante deficiência deste íon pode mesmo ocorrer com níveis séricos normais. Assim, a determinação da concentração de magnésio plasmático é considerada índice específico, porém pouco sensível, do conteúdo corporal do magnésio (23). No presente estudo, entretanto, a magnesemia esteve diminuída numa proporção de pacientes maior do que aqueles com magnésio intracelular baixo. É possível que o fato de os pacientes apresentarem glicemias elevadas e déficit na secreção de insulina tenha influenciado neste achado. Em trabalho anteriormente publicado, a prevalência da deficiência de magnésio também foi maior no soro, apesar da média dos níveis intracelulares estarem diminuídos quando comparados à população controle (24).

Optamos pela determinação do magnésio em células mononucleares, nas quais há predomínio de linfócitos, por ser uma técnica já utilizada em nosso meio (24), e pela boa correlação com o magnésio determinado em biópsia de músculo. Esta seria o padrão ouro para avaliação intra-celular do íon; entretanto é uma técnica invasiva $(25,26)$.

Outro objetivo deste trabalho foi pesquisar a correlação entre concentrações circulantes de magnésio e a resistência à insulina. Vários trabalhos sugerem esta associação $(2,13,18,27)$, apesar de a maior parte dos investigadores pesquisar a associação com magnésio plasmático, que sabidamente não representa bem o conteúdo corporal do magnésio, que é um íon predominantemente intra-celular.
Neste estudo, observamos correlação negativa entre magnésio linfocitário e índice de massa corpórea, e uma tendência para correlação inversa entre o magnésio linfocitário e o HOMA r, parâmetro utilizado para avaliação de resistência à insulina, que talvez não tenha alcançado significância estatística em função do número pequeno de pacientes. Não observamos correlação entre o magnésio plasmático e o HOMA r, nem com o HOMA B.

A escolha do HOMA r para avaliação laboratorial da resistência à insulina deveu-se à facilidade do método e do seu reconhecimento na literatura como bom marcador da sensibilidade periférica dos tecidos à ação da insulina $(19,28)$. Uma limitação deste estudo reside no fato de que, em sendo um trabalho originado de um banco de dados pré-existente, não dispomos de outros dados clínicos e laboratoriais da síndrome metabólica como medida da circunferência abdominal, triglicérides ou HDL séricos, para avaliarmos sua correlação com os níveis de magnésio.

Conclui-se, portanto, que, em função da freqüência elevada de deficiência de magnésio, a sua determinação preferencialmente em compartimento intra-celular seria de grande utilidade no paciente com diabetes mellitus. Sendo a síndrome metabólica um preditor do desenvolvimento do diabetes mellitus, é possível que a determinação do mesmo também seja útil nestes pacientes, mesmo com glicemias de jejum ainda normais. Entretanto, a determinação intracelular é complexa, devendo ser reservada apenas para pesquisa. Uma vez que é um método específico, apesar de pouco sensível, concordamos com os autores que sugerem a determinação do magnésio plasmático em pacientes com diabetes mellitus (3) ao menos duas vezes ao ano. A medida da magnesemia em indivíduos com síndrome metabólica deve ser avaliada.

A American Diabetes Association recomenda determinação do magnésio nos pacientes com maior risco de hipomagnesemia e o seu tratamento, quando detectada a deficiência do íon (29). Questiona-se, todavia, se a reposição do magnésio não teria efeito benéfico mesmo naqueles pacientes com níveis séricos normais. Os estudos são conflitantes $(3,11,30$, 31 ), apesar de a grande maioria dos autores mostrar efeito positivo na reposição do magnésio nesta população. Mais trabalhos, entretanto, são necessários para avaliar a relação custo-benefício da determinação e da reposição do magnésio nestes pacientes. Por outro lado, se comprovada deficiência de magnésio na síndrome metabólica, a hipótese da reposição deste íon na prevenção do diabetes mellitus tipo 2 deve ser avaliada. 


\section{REFERÊNCIAS}

1. Mooradian A, Failla M, Hoogwerf B, Maryniuk M, WylieRoset J. Selected vitamins and minerals in diabetes. Diabetes 1994; 17:464-74.

2. Barbagallo $M$, Dominguez $L$, Galioto $A$, Ferlisi $A$, Cani $C$, Malfa L, et al. Role of magnesium in insulin action, diabetes and cardio-metabolic syndrome X. Mol Aspec Med 2003;24:39-52.

3. Rodriguez-Moran M, Guerrero-Romero F. Oral Magnesium Supplementation improves insulin sensitivity and metabolic control in type 2 diabetic subjects. Diabetes Care 2003;26:1147-51.

4. Mather $\mathrm{H}$, Nisbet JA, Burton GH, Poston GJ, Bland JM, Bailey PA, et al. Hypomagnesemia in diabetes. Clin Chem Acta 1979;95:235-42.

5. Levin $G$, Mather $H$, Pilkington TRE. Tissue magnesium status in diabetes mellitus. Diabetologia 1981;21:131-4.

6. McNair P, Christensen M, Christiansen C, Madsbad S, Transbol I. Renal hypomagnesemia in human diabetes mellitus: its relation to glucose homeostasis. Eur J Clin Invest 1982;12:81-5.

7. Herrera Pombo J, Defillo G, Rapado A. Trastorno electivo en transporte tubular renal de magnesio en la diabetes mellitus. Rev Clin Espan 1983; 169:173-5.

8. Vanroelen L, Gaal L, Van Rooy P, De Leeuw I. Serum and erythrocyte magnesium level in type I and type II diabetics. Acta Diabetol 1985;22:185-90.

9. Resnick L, Altura BT, Gupta R, Laragh J, Alderman M, Altura BM. Intracellular and extracellular magnesium depletion in type 2 (non-insulin dependent) diabetes mellitus. Diabetologia 1993;36:767-70.

10. Lima ML, Pousada J, Barbosa K, Canguçú V, Prado V, Menezes $M$, et al. Correlação entre níveis plasmáticos de magnésio e controle glicêmico. IX Congresso da Associação Latinoamericana de Diabetes. Foz do Iguaçu, 1995, Livro de Resumos.

11. Lima ML, Cruz T, Pousada JC, Rodrigues LE, Barbosa K, Canguçú $\vee$. The effect of magnesium supplementation in increasing doses on the control of type 2 diabetes. Diabetes Care 1998;21:682-6.

12. Kao WH, Folsoma $\mathrm{R}$, Nieto FJ, Watson RL, Brancati FL. Serum and dietary magnesium and the risk of type 2 diabetes mellitus and atherosclerose risk in community study. Arch Intern Med 1999; 159:2151-9.

13. Song Y, Manson JE, Buring JE, Liu S. Dietary Magnesium Intake in relation to plasma insulin levels and risk of type 2 diabetes in Women. Diabetes Care 2004;27:59-65.

14. Meigs JB. The Metabolic Syndrome. BMJ 2003;327:61-2.

15. Bloomgarden Z. The 1st World Congress on the Insulin Resistance Syndrome. Diabetes Care 2004;27:602-9.

16. Hauner $H$. Insulin resistance and the metabolic syndrome - a challenge of the new millennium. Eur J Clin Nutr 2002;56:525-9.

17. Alexander $\mathrm{C}$. The coming of age of the metabolic syndrome. Diabetes Care 2003;26:3180-1.

18. Guerrero-Romero F, Moran-Rodriguez M. Low serum magnesium levels and metabolic syndrome. Acta Diabetologica 2002;39:209-13.
19. WHO. Identification, enumeration and isolation of $\mathrm{B}$ and T Iymphocytes from human peripheral blood. Report of a WHO/IARC Sponsored workshop on human B and T cell; 1974

20. Rodrigues LEA, Mathias CMC, Amorim MSP. Modificação do método de Lowry para a quantificação de proteínas. Rev Bras Patol Clín 1989:25:1.

21. Mathews DR, Hosker JP, Rudenski AS, Naylor BA Treacher DF, Turner RC. Homeostasis model assessment: insulin resistance and b-cell function from fasting plasma glucose and insulin concentrations in man. Diabetologia 1985;28:412-9.

22. Quon MJ. Limitations if the fasting glucose to insulin ratio as an index of insulin sensitivity (editorial). J Clin Endocrinol Metab 2001;86:4615-7.

23. Reinhart R, Marx J, Haas R, Desbiens N. Intracellular magnesium of mononuclear cells from venous blood of clinically health subjects. Clin Chem Acta 1987; 167:187-95.

24. Menezes M. Comportamento do magnésio linfocitário e plasmático no infarto agudo do miocárdio (Mestrado). UFBa, 1985.

25. Sjögren AS, Floren CH, Nilsson A. Measurements of magnesium in mononuclear cells. Sci Environ $1985 ; 42: 77-82$

26. Câmara EM, Cruz T, Nassri M, Rodrigues LE. Muscle magnesium content and cardiac arrhytmias during treatment of congestive heart failure due to chronic chagasic cardiomyopathy. Braz J Med Biol Res 1996; 19:49-58.

27. Paolisso G, Sgambato S, Pizza G, Passarielo N, Varrichio $\mathrm{M}, \mathrm{D}^{\prime}$ Onófrio $\mathrm{F}$. Improved insulin response and action by chronic magnesium administration in aged NIDDM subjects. Diabetes Care 1989; 12:265-99.

28. Hafner S, Gonzalez C, Miettinen H, Kennedy E, Stern M. A prospective analysis of the HOMA model. Diabetes Care 1996; 19:1138-41.

29. American Diabetes Association (ADA). Magnesium supplementation in the treatment of diabetes. Diabetes Care 1992; 15:1065-7.

30. Paolisso G, Passarielo N, Pizza G, Marazzo G, Guinta R, Sgambato $S$, et al. Dietary magnesium supplements improve b cell response to glucose and arginine in elderly non-insulin dependent diabetic subject. Acta Endocrinol (Copenh) 1989;121:16-20.

31. Gullestad L, Jacobsen T, Dolva LO. Effect of magnesium treatment on glycemic control and metabolic parameters in NIDDM patients. Diabetes Care 1994;17:460-1.

32. Eibl NL, Kopp HP, Nowak HR, Schnack CJ, Hopmeier PG, Schernthaner $G$. Hypomagnesemia in type II diabetes: effect of a 3-month replacement therapy. Diabetes Care 1995; 18:188-92.

\section{Endereço para correspondência:}

Maria de Lourdes Lima

Rua Cel. Arthur G. de Carvalho 537/402

41820-190 Salvador, BA

E-mail: mlourdeslima@hotmail.com 